\title{
Análise comparativa da obra espírita Nosso Lar e duas de suas versões em língua inglesa
}

\section{Comparative analysis of the Spiritist book Nosso Lar and two of its English versions}

“... recordemos que o Espiritismo nos solicita uma espécie permanente de caridade - a caridade da sua própria divulgação."

Emanuel

Ana Luiza da Silveira* Patrícia Viana Belam*

Resumo: 0 presente estudo objetiva analisar quais foram os procedimentos tradutórios utilizados em duas versões para a língua inglesa da obra Nosso Lar, psicografada pelo médium Chico Xavier e ditada pelo espírito André Luiz. As versões receberam o nome de Nosso Lar - Life in the spirit world e Astral City. A pesquisa apoia-se em estudos sobre a doutrina e a literatura espírita, os procedimentos técnicos da tradução trazidos por Barbosa (2004), o conceito de paratexto de Bastianetto (2005) e os conceitos de Venuti (2002) sobre domesticação e estrangeirização do texto traduzido. Os resultados apontaram para o uso de procedimentos variados, e revelam uma tendência à estrangeirização por parte de uma das versões e à domesticação por parte de outra. A área acadêmica necessita de

\footnotetext{
Graduanda do Curso de Letras-Tradutor da Universidade do Sagrado Coração (USC). analuizadasilveira@gmail.com

"* Prof. ${ }^{a}{ }^{D r}{ }^{\mathrm{a}}$ e Coordenadora do Curso de Letras-Tradutor da Universidade do Sagrado Coração (USC). patricia.belam@gmail.com
} 
mais trabalhos na área da tradução da literatura espírita, justificando-se, portanto, a realização deste estudo.

Palavras-chave: Literatura espírita; Nosso Lar; Tradução; Análise comparativa; Procedimentos técnicos.

Abstract: The present study aims to analyze which translation procedures were used in two English versions of the book Nosso Lar, psychographed by the medium Chico Xavier and dictated by the spirit Andre Luiz. These versions are titled Nosso Lar - Life in the spirit world and Astral City. This research is based on studies about the Spiritist doctrine and literature, the technical translation procedures by Barbosa (2004), the paratext concept by Bastianetto (2005) and the domestication and foreignization concepts by Venuti (2002). The results revealed the use of various procedures and indicated opposite tendencies on each version regarding the use of the foreignization and domestication concepts. The academic context needs more studies in this specific area - translation of Spiritist literature, justifying, therefore, the accomplishment of this study.

Keywords: Spiritist literature; Nosso Lar; Translation; Comparative analysis; Technical procedures.

\section{Introdução}

Desde 1939, o ano de sua constituição, a editora da Federação Espírita Brasileira (FEB) já publicou 10 milhões de cópias somente das obras da codificação espírita, além de cerca de 35 milhões de obras de 160 autores, de acordo com seu próprio site. Entre romances, crônicas, textos científicos e filosóficos, existem obras traduzidas para o espanhol, francês, inglês, russo, esperanto e húngaro ${ }^{1}$. Com o crescimento contínuo da literatura espírita no cenário brasileiro e mundial, a necessidade de traduções e versões que acompanhem essa produção é intensificada. Ao mesmo tempo, existem poucos trabalhos acadêmicos que abordem a tradução nessa área, justificando-se, portanto, a realização deste trabalho.

Objetivamos, dessa maneira, contribuir para a área acadêmica da tradução de literatura espírita e, para tanto, iremos analisar os procedimentos tradutórios utilizados em duas versões para a língua inglesa do livro Nosso Lar, psicografado pelo médium Chico Xavier e ditado pelo espírito de André Luiz (XAVIER 1992).

\footnotetext{
${ }^{1}$ FEB Editora, c2017. Editora cujo objetivo é a promoção do estudo, da prática e da difusão do Espiritismo. Disponível em: 〈http://www.febnet.org.br〉. Acesso em: 26 jul. 2017.
} 
Esta pesquisa apoia-se em estudos sobre a doutrina espírita e a literatura espírita, com os trabalhos de Silva (1997) e Lewgoy (2008), e sobre a literatura espírita e tradução, com Vieira e Jesus (2013). Fundamenta-se, ainda, nos estudos sobre os procedimentos técnicos da tradução trazidos por Barbosa (2004), no conceito de paratexto de Bastianetto (2005) e na obra de Venuti (2002) sobre a domesticação e a estrangeirização de um texto.

Utilizaremos o método comparativo para analisar quais foram os procedimentos tradutórios utilizados em duas versões para a língua inglesa do livro Nosso Lar: Nosso Lar - Life in the spirit world e Astral City.

De acordo com a Federação Espírita Brasileira (FEB, 2012), “o Espiritismo é uma Ciência que trata da natureza, origem e destino dos Espíritos, bem como de suas relações com o mundo corporal".

Allan Kardec foi o pseudônimo adotado pelo pesquisador francês Hippolyte Leon Denizard Rivail, que atentamente estudou fenômenos espíritas que ocorriam na Europa do século XIX e identificou que se tratava de espíritos dos homens que haviam morrido. 0 estudioso fez centenas de perguntas aos espíritos, analisou minuciosamente as respostas, comparou-as e codificou-as, compondo, assim, os cinco livros básicos da doutrina espírita, conhecidos como Pentateuco Kardequiano (FEB 2012). São eles: O Livro dos Espíritos, $O$ Livro dos Médiuns, O Evangelho Segundo o Espiritismo, O Céu e o Inferno e $A$ Gênese.

Segundo Lewgoy (2008), o espiritismo foi introduzido no Brasil na segunda metade do século XIX, estando presente em mais de 30 países. A consolidação do espiritismo no Brasil é tanta que sua influência atinge até mesmo o espiritismo francês, que depende dele para respaldar suas pretensões de legitimidade.

Ainda segundo o autor, isso não quer dizer que o Brasil seja mítico e puro, mas que há uma grande exportação das referências espíritas produzidas na experiência histórica brasileira, tais como o modelo federativo da FEB, a forma de organização e funcionamento das casas espíritas e a incorporação do patrimônio bibliográfico do espiritismo brasileiro, especialmente as obras psicografadas dos médiuns Chico Xavier e Divaldo Franco. Por servir de 
modelo para outros países, a literatura espírita produzida em nosso país possui grande prestígio perante a comunidade espírita.

A literatura que chamamos de "literatura espírita" é aquela, mediúnica ou não, que possui um compromisso claro com a divulgação da doutrina ou dos fenômenos espíritas em seu tríplice aspecto: filosófico, científico e religioso (LEAL C2017).

De acordo com Silva (1997: 3):

A doutrina espírita foi codificada em livros e textos de natureza variada, sobretudo obras concebidas "psicograficamente", através de um médium que escreve mensagens, poesias, textos literários, provenientes da inteligência consciente de desencarnados. No Brasil, sobretudo após os anos 30, um intenso movimento literário espírita desta natureza implantou-se através de inúmeras editoras, voltadas para a divulgação do Espiritismo.

Estudos acadêmicos realizados na área da literatura espírita incluem o artigo "Fé e leitura: a literatura espírita e o imaginário religioso", escrito por Silva (1997), que nos apresenta os gêneros da literatura espírita e explica como se desenvolveram no país.

Entre os importantes nomes da literatura espírita nacional, encontramos o médium Chico Xavier, que psicografou, dentre inúmeros outros, os livros da Série André Luiz. Um deles é o livro Nosso Lar, objeto deste estudo, eleito o melhor livro espírita do século XX e que tem o mérito de ter sido a primeira grande descrição do plano espiritual que influenciou, de maneira decisiva, os estudos e as pesquisas espíritas brasileiras e mundiais (MENSAGEIRO 2000).

Essa obra conta, em detalhes, ao longo de 50 capítulos, como foram os primeiros anos de André Luiz (pseudônimo adotado por um médico que viveu no Rio de Janeiro) na Colônia Espiritual Nosso Lar. Sua primeira edição é de 1944 e, atualmente, está na 64ª edição. Em 2003, a obra alcançou a expressiva marca de 1,5 milhão de exemplares (KüHL c2017).

Conforme dados coletados no site da Editora FEB, constam, em seu histórico, 10 milhões de cópias somente das obras da codificação espírita e

2 "Conjunto de textos atribuído a espíritos desencarnados que se comunicaram através de um médium psicógrafo consciente ou inconsciente", de acordo com o site Correio Espírita.

3 “(...) a transmissão do pensamento do Espírito, mediante a escrita feita com a mão do médium” (Feb c2017). 
cerca de 35 milhões de obras de 160 autores. Entre romances, mensagens, contos, crônicas, textos científicos e filosóficos, existem obras traduzidas para o espanhol, francês, inglês, russo, esperanto e húngaro (QUEM 2016).

A tradução da literatura espírita pertence à área da tradução literária, na qual encontram-se letras de música, poemas, contos e livros dos mais variados temas. Essa área da tradução pode ser considerada uma das mais complexas devido aos inúmeros desafios apresentados. Para superar esses desafios, o tradutor poderá utilizar todos os recursos técnicos disponíveis para produzir, no leitor da língua-alvo, efeitos estilísticos pelo menos semelhantes aos causados no leitor da língua-fonte (BRITTO 2012).

Apesar da produção de livros da literatura espírita e de suas traduções estarem em constante crescimento, a realização de trabalhos acadêmicos sobre a tradução nessa área parece, ainda, não acompanhar esse crescimento.

No entanto, um artigo dessa área auxiliará no aporte teórico deste trabalho. É o estudo de Vieira e Jesus (2013). Esse trabalho teve o objetivo de realizar uma análise contrastiva da referida obra e uma de suas traduções para o inglês, The Astral City. Com a finalidade de construir um glossário bilíngue, o trabalho identificou o vocabulário específico do Espiritismo através do concordanciador AntConc e selecionou 100 palavras para a criação de um glossário simples e 10 palavras que foram detalhadas em fichas terminológicas. Como resultado da pesquisa, as autoras analisaram que a maioria dos termos utilizados para descrever o plano metafísico são termos de língua geral e que eles se tornam termos específicos quando no contexto religioso. As autoras também observaram que as traduções de alguns termos foram inconsistentes em alguns momentos e sugeriram que fossem feitas outras pesquisas como forma de contribuir para a melhoria das traduções no meio religioso. 


\section{Fundamentação teórica}

Para que possamos realizar a análise pretendida neste artigo, nos apoiaremos nos procedimentos tradutórios descritos por Barbosa (2004). Seu livro, como a própria autora menciona, constitui uma pequena tentativa de recaracterização e de recategorização dos procedimentos técnicos da tradução, inicialmente descritos por Vinay e Darbelnet (1958 apud BARBOSA 2004). Iremos conceituar, a seguir, os procedimentos relevantes para a nossa análise.

Segundo Aubert (1987 apud BARBOSA 2004: 65), tradução literal é "aquela em que se mantém uma fidelidade semântica estrita, adequando, porém, a morfo-sintaxe [sic] às normas gramaticais da LT”.

Vários autores parecem repudiar essa tradução literal, principalmente Vázquez-Ayora (1977 apud BARBOSA 2004: 65), que acredita que esta seria a fonte de todos os erros na tradução. Entretanto, conforme Aubert (1987 apud BARBOSA 2004: 65) e Newmark (1988 apud BARBOSA 2004: 65), ela pode ser necessária, como em edições bilíngues, que têm por objetivo a comparação com o texto original, ou até obrigatória, como na tradução de certos documentos. Para Newmark (1988 apud BARBOSA 2004: 65), é o procedimento recomendado sempre que possível.

0 procedimento da equivalência consiste em substituir um segmento de texto da língua original (LO) por um outro segmento da língua traduzida (LT) que não o traduz literalmente, mas que the é funcionalmente equivalente (BARBOSA 2004: 67) e pode ser utilizado em expressões idiomáticas e provérbios, por exemplo.

Em relação aos procedimentos omissão vs. explicitação, Vázquez-Ayora (1977 apud BARBosA 2004: 68) define que a omissão consiste em omitir elementos do texto na língua original (TLO) desnecessários ou excessivamente repetitivos, do ponto de vista da LT. É usada na tradução do inglês para o português dos pronomes pessoais, por exemplo, pois muitas vezes são 
dispensáveis quando exercem a função do sujeito. Já na tradução do português para o inglês, seria necessária a explicitação do pronome, já que sua presença é obrigatória no inglês.

Já o procedimento de transferência consiste na introdução de material textual da LO na LT. A denominação de "transferência" para esse procedimento era a preferida por Newmark. Esse procedimento é subdividido em estrangeirismo, estrangeirismo transliterado (transliteração), estrangeirismo aclimatado (aclimatação), estrangeirismo + uma explicação de seu significado, ou transferência com explicação, dividida em nota de rodapé e diluição do texto (NeWMARK 1988 apud BARBOSA 2004: 71).

O estrangeirismo consiste em transferir ou copiar vocábulos ou expressões do TLO referentes a um conceito, técnica ou objeto que são desconhecidos para os falantes da LT. A transliteração, em substituir uma convenção gráfica por outra e ocorre em casos de extrema divergência entre duas línguas que nem sequer têm um alfabeto comum, conforme Catford (1965 apud BARBOSA 2004: 73). A aclimatação, conhecida também por decalque, consiste em adaptar um radical estrangeiro à fonologia e à estrutura morfológica da língua que o importa, de acordo com Câmara Junior (1977 apud BARBOSA 2004: 73). O objetivo do estrangeirismo + explicação é que o leitor possa aprender seu significado por meio do contexto. 0 tradutor pode optar pela inclusão de uma nota de rodapé no final do capítulo ou ao final do livro ou, ainda, diluir a explicação no próprio texto. A adaptação é um procedimento considerado por Barbosa (2004) como sendo o limite extremo da tradução e deve ser aplicado em casos em que a situação toda a que se refere a TLO não existe na realidade extralinguística dos falantes da LT, recriando-se, portanto, uma outra situação equivalente que seja presente na realidade extralinguística da LT.

Além dos procedimentos descritos acima, nos apoiaremos em teoria sobre paratextos, com enfoque nas notas de rodapé. 0 paratexto é definido por Maingueneau (2001: 81 apud BASTIANETTO 2005: 54) como um "conjunto de fragmentos verbais que acompanham o texto propriamente dito". Esses fragmentos verbais são constituídos pelo título, subtítulo, prefácio, posfácio, 
encartes, sumário, etc. Para o autor, existem dois tipos de paratexto, o "paratexto autoral" e o "paratexto editorial". 0 autoral contém textos produzidos pelo autor, isto é, título, epígrafe, prefácio, dedicatória, notas de rodapé, etc. Já o paratexto editorial contém os textos produzidos pelo editor, como textos figurando na capa ou na orelha da obra, informações da ficha catalográfica, índice e copyright, dentre outros, inclusive as notas do tradutor (BASTIANETTO: 2005).

O paratexto editorial apresenta ao leitor, no caso específico das notas do tradutor, "aquilo que o tradutor julga ser de difícil compreensão para o leitor estrangeiro", conforme Bastianetto (2005). Essas notas podem auxiliar o leitor estrangeiro a compreender de forma mais clara o conteúdo de difícil assimilação e o que está implícito no texto original.

As notas de rodapé apresentam ao leitor do texto traduzido os mesmos dados apresentados aos leitores do texto original e, de acordo com a autora, fazem parte do texto, mesmo que apenas o contornem, e devem ser tratadas como tal na versão traduzida. Diversamente, o leitor pode atribuir sua autoria ao editor. Porém, elas, por si sós, não garantem que o leitor irá entender o que ali consta, já que o conhecimento prévio dos leitores das línguas original e traduzida não é o mesmo (BASTIANETTO: 2005).

Entendemos, então, que tanto as notas de rodapé autorais, quanto as notas do tradutor, atuam no processo de compreensão do leitor. Essa compreensão, de acordo com Bastianetto (2005), abrange os conhecimentos linguísticos, o conhecimento prévio do assunto tratado, o conhecimento geral a respeito do mundo, a motivação e o interesse na leitura.

Dessa forma, também analisaremos se os tradutores das duas versões utilizaram as notas de rodapé e de que maneira elas integraram o processo tradutório.

Sobre os conceitos de domesticação e estrangeirização do texto traduzido, Venuti (2002) afirma que cada texto é produzido em determinado contexto e carrega características próprias de sua cultura atual; por isso, o significado desse mesmo texto, quando traduzido, não será exatamente o mesmo. Segundo o autor (2002: 120), "a tradução imita os valores linguísticos 
e literários de um texto estrangeiro, mas a imitação é moldada numa língua diferente que se relaciona a uma tradição cultural diferente".

Quando o tradutor promove as diferenças culturais e linguísticas de um texto estrangeiro, ele o estrangeiriza e quando ele reprime essas diferenças, ele o domestica. Logo, a estrangeirização mantém os traços culturais da língua estrangeira no texto traduzido enquanto a domesticação os reprime para facilitar a leitura, eliminando os elementos que possam prejudicar seu entendimento.

Acreditamos que esses conceitos nos ajudarão a observar qual posição os tradutores tomaram ao adotarem determinados procedimentos tradutórios nas duas versões a serem analisadas neste estudo.

\section{Metodologia}

O presente estudo possui natureza qualitativa e exploratória, e utilizará o método da análise comparativa para observar quais foram, com base na teoria de Barbosa (2004), os procedimentos tradutórios utilizados em duas versões para a língua inglesa do livro Nosso Lar, psicografado pelo médium Chico Xavier e ditado pelo espírito de André Luiz. Para isso, selecionamos dois livros distintos: Nosso Lar - Life in the spirit world, traduzido por Darrel W. Kimble e Marcia M. Saiz e lançado pela editora International Spiritist Council, em 2010 (XAVIer 2010); e Astral City, traduzido por Evelyn Morales et al. e lançado como $1^{\text {st }}$ Electronic Edition pelo GEAE (Advanced Study Group of Spiritism - Grupo avançado de estudos espíritas), no ano 2000 (XAVIER 2000). Ambos foram lançados em formato digital (respectivamente, em epub e pdf).

Para realizar a análise, selecionamos alguns trechos do livro original e de seus correspondentes em língua inglesa em ambas as versões e faremos um quadro comparativo para melhor elucidação. A análise está composta por um quadro dividido em três partes, trazendo o original e os excertos das duas versões da primeira categoria. As notas de rodapé possuem quadros 
diferentes, adaptados às necessidades da análise. Após cada quadro, traremos a análise quanto aos procedimentos tradutórios que cada versão utilizou.

Além da análise dos procedimentos técnicos utilizados nos trechos selecionados, apresentaremos quais notas de rodapé foram feitas pelo autor do livro original, se as mesmas foram mantidas nas duas versões e se outras notas foram acrescentadas pelos tradutores. Em caso positivo, analisaremos de que maneira elas integraram o processo tradutório.

\section{Análise e discussão dos dados}

Para melhor organização, dividimos a análise em duas categorias. Dessa forma, analisaremos, a seguir, quais foram as escolhas dos tradutores em relação aos termos específicos do espiritismo que foram traduzidos e como as notas de rodapé foram abordadas no original e nas duas versões. Apontaremos, em todas as análises, quais foram os procedimentos tradutórios utilizados pelos tradutores.

Chamaremos a versão Nosso Lar - Life in the spirit world de Versão A e a versão Astral City de Versão B.

\subsection{Termos específicos}

\section{Quadro 1 - Obsidiado (grifo nosso)}

\begin{tabular}{|l|l|l|}
\hline \multicolumn{1}{|c|}{ ORIGINAL } & $\begin{array}{c}\text { NOSSO LAR - LIFE IN THE } \\
\text { SPIRIT WORLD } \\
\text { (Versão A) }\end{array}$ & \multicolumn{1}{c|}{$\begin{array}{c}\text { ASTRAL CITY } \\
\text { (Versão B) }\end{array}$} \\
\hline $\begin{array}{l}\text { (...) Que os pobres } \\
\text { obsidiados nas aberrações } \\
\text { sexuais costumam chegar em } \\
\text { extrema loucura? P.36 }\end{array}$ & $\begin{array}{l}\text { And that those who were } \\
\text { obsessed with sexual } \\
\text { aberrations usually arrive } \\
\text { completely insane? P.67 }\end{array}$ & $\begin{array}{l}\text { Still others who have lived } \\
\text { sexually depraved lives } \\
\text { enter spirit life totally } \\
\text { insane. P. 32 }\end{array}$ \\
\hline
\end{tabular}


Para analisarmos as escolhas tradutórias do termo acima destacado, é importante trazermos a definição da palavra "obsidiado" na linguagem geral e na linguagem espírita em ambas as línguas portuguesa e inglesa.

Para tanto, primeiramente buscamos sua definição no Dicionário Aulete Digital e no site da FEB, ambos em língua portuguesa. O dicionário não apresenta a definição para a referida palavra, porém apresenta a definição da palavra "obsidiador" como sendo "aquele que assedia, importuna, molesta" (OBSIDIADO c2017). Na linguagem espírita, o site da FEB traz a definição "o Espírito obsidiado tem o seu perispírito impregnado, saturado de fluidos maus e perniciosos" e também "Obsidiado/Obsesso: importunado, atormentado, perseguido" (VoCÁBULOS C2016).

A definição dada para o termo obsessed pelo dicionário de língua inglesa Cambridge Dictionary (OBSESSED C2017) foi "to think about someone or something all the time" (pensar em alguém ou algo o tempo todo "obcecado", em língua portuguesa, tradução nossa), sendo uma acepção usada em uma linguagem mais comum, mas que não carrega a mesma carga semântica do termo utilizado no contexto espírita. Na falta de um glossário normatizado dos termos específicos da doutrina espírita, trouxemos sua definição presente em dois livros vertidos para a língua inglesa, que são referência na disseminação da doutrina espírita: The Spirits Book ( $O$ Livro dos Espíritos) e Obsession, Passes, Counseling (Obsessão, o passe, a doutrinação).

Encontramos, no livro The Spirits Book, o conceito de obsessed na pergunta 474 (Kardec 1996: 229), com o sentido de influência de um espírito malfeitor sobre as ações de uma pessoa:

474. If there be no such thing as "possession", in the ordinary sense of that term-that is to say, cohabitation of two spirits in the same body-is it possible for one soul to find itself dominated, subjugated, obsessed by another soul to such a point as that its will is, so to say, paralysed?

"Yes; and it is this domination which really constitutes what you call possession. But you must understand that this domination is never established without the participation of the spirit who is subjected to it, either through his weakness ${ }^{1}$ or his free-will."

474. Desde que não há possessão propriamente dita, isto é, coabitação de dois Espíritos no mesmo corpo, pode a alma ficar na dependência de outro Espírito, de modo a se achar subjugada ou 
obsidiada ao ponto de a sua vontade vir a achar-se, de certa maneira, paralisada? "Sem dúvida e são esses os verdadeiros possessos. Mas, é preciso que saibas que essa dominação não se efetua nunca sem que aquele que a sofre o consinta, quer por sua fraqueza, quer por desejá-la. Muitos epilépticos ou loucos, que mais necessitavam de médico que de exorcismos, têm sido tomados por possessos." (KARDEC 2004: 311, grifo nosso).

\section{O livro Obsession, Passes, Counseling (Obsessão, o passe, a} doutrinação) complementa a definição do termo:

The causes of obsession are the result of some factors, among which the most frequent are: problems of reincarnation, vicious trend, extreme egoism, unmeasured ambitions, aversion to certain people, hatred, feelings of revenge, frivolity, exaggerated vanity, attachment to earthly values and so on (PIRES 2004: 7, grifo nosso).

"As causas da obsessão decorrem de vários fatores, dos quais os mais frequentes são: problemas reencarnatórios, tendências viciosas,egoísmo excessivo, ambições desmedidas,aversão a certas pessoas, ódio, sentimentos de vingança, futilidade, vaidade exagerada, apego ao dinheiro e assim por diante (PIRES 2009: 10).

Percebemos, então, que, de forma recorrente, conforme afirmam Vieira e Jesus (2013), os termos utilizados para descrever o plano metafísico no Espiritismo são termos de língua geral que se tornam específicos em contexto e que, no contexto espírita, o termo é bem mais complexo e possui uma carga muito mais forte do que na linguagem comum.

Constatamos que a Versão A utilizou-se do procedimento da equivalência, que de acordo com Barbosa (2004: 67), "consiste em substituir um segmento de texto da LO por outro segmento da LT que não o traduz literalmente, mas que the é funcionalmente equivalente", ao traduzir a palavra "obsidiado" por obsessed, pois, dentro do contexto espírita, recebem a mesma carga semântica. Em contrapartida, a Versão B, provavelmente com a intenção de utilizar-se do mesmo procedimento técnico, traduziu, de maneira equivocada, a palavra "obsidiado" por depraved, que significa "depravado", produzindo uma conotação diferente de seu verdadeiro sentido. Isso porque, como vimos anteriormente, o termo "obsidiado" é bastante significativo no contexto espírita e carrega uma forte carga no seu conceito. A pessoa que está sendo obsidiada sofre influências externas e passa a ser provocada a dizer, sentir e pensar coisas que são embutidas em seu 
pensamento; portanto, ela não é necessariamente "depravada", pois mesmo tendo sua parcela de culpa em suas ações, ela está em posição de vítima, influenciada por um espírito malfeitor e mais forte que ela.

Portanto, observamos que nessa análise, a Versão A foi a que trouxe a tradução mais adequada para o termo em questão.

Passaremos, agora, à análise do termo "desencarnado" e suas versões em língua inglesa nas duas obras.

\section{Quadro 2 - Desencarnado (grifo nosso)}

\begin{tabular}{|l|l|l|}
\hline ORIGINAL & $\begin{array}{c}\text { NOSSO LAR - LIFE IN THE } \\
\text { SPIRIT WORLD } \\
\text { (Versão A) }\end{array}$ & \multicolumn{1}{|c|}{$\begin{array}{l}\text { ASTRAL CITY } \\
\text { (Versão B) }\end{array}$} \\
\hline $\begin{array}{l}\text { (..) Há regiões múltiplas } \\
\text { para os desencarnados, } \\
\text { como existem planos } \\
\text { inúmeros e surpreendentes } \\
\text { para as criaturas envolvidas } \\
\text { de carne terrestre. P. 45 }\end{array}$ & $\begin{array}{l}\text { There are many, many } \\
\text { regions for discarnates, just } \\
\text { as there are innumerable and } \\
\text { surprising planes for for fiscarnate Spirits, just } \\
\text { incarnates. P. 75 }\end{array}$ & $\begin{array}{l}\text { There are countless planes } \\
\text { for disere many wondrous } \\
\text { as there are mans for those still in } \\
\text { regions } \\
\text { flesh. P. 38 }\end{array}$ \\
\hline
\end{tabular}

Segundo o site Instituto André Luiz, "Desencarnação é libertação da alma, morte é outra coisa. Morte constitui cessação da vida, apodrecimento, bolor!" (LUIz C2017). Na linguagem geral, a palavra discarnate já traz uma acepção religiosa em seu significado e, de acordo com o dicionário MerriamWebster, significa "having no physical body" (sem corpo físico, tradução nossa) (DISCARNATE c2017).

Observamos que a Versão A utilizou o procedimento da tradução literal. Essa tradução, conforme Aubert (1987 apud BARBOSA 2004), é aquela em que se mantém uma fidelidade semântica estrita, adequando, porém, a morfossintaxe às normas gramaticais da LT. Por outro lado, a Versão B utilizou o procedimento da equivalência. Esse procedimento é descrito por Barbosa (2004) e consiste em substituir um segmento de texto da LO por outro segmento da LT que não o traduz literalmente, mas que the é funcionalmente equivalente. Conforme Vieira e Jesus (2013: 15), “[...] parece não haver muitos termos específicos da descrição do mundo espiritual. Para fazer essa descrição, acrescentam-se determinantes como -espiritual ou -do espírito". 
Conclui-se, portanto, que o acréscimo de spirits foi introduzido pela Versão B para adequar o termo discarnate à linguagem espírita.

A seguir, prosseguiremos com a análise do último termo desta categoria, o termo "Umbral".

Primeiramente, é necessário esclarecer que esse próximo termo também é utilizado na língua geral, porém em sentido diferente do que na doutrina espírita. Vamos conceituá-lo na linguagem geral e na concepção espírita e, então, analisaremos os procedimentos tradutórios empregados.

É importante destacar, também, que o termo "Umbral" foi introduzido na doutrina espírita a partir do lançamento do livro objeto deste estudo, uma vez que foi o autor desencarnado, André Luiz, que explicou o que é e como funciona o Nosso Lar e explicou, inclusive em um capítulo próprio, o que é e como funciona o Umbral. 0 trecho selecionado faz parte de um diálogo entre o autor e um de seus amigos do plano espiritual, presente no capítulo acima mencionado, de número 12.

\section{Quadro 3 - Umbral (grifo nosso)}

\begin{tabular}{|c|c|c|}
\hline ORIGINAL & $\begin{array}{l}\text { NOSSO LAR - LIFE IN THE } \\
\text { SPIRIT WORLD } \\
\text { (Versão A) }\end{array}$ & $\begin{array}{l}\text { ASTRAL CITY } \\
\text { (Versão B) }\end{array}$ \\
\hline $\begin{array}{l}\text { (...) O Umbral - continuou } \\
\text { ele, solícito - começa na } \\
\text { crosta terrestre. É a zona } \\
\text { obscura de quantos no } \\
\text { mundo não se resolveram a } \\
\text { atravessar as portas dos } \\
\text { deveres sagrados, a fim de } \\
\text { cumpri-los, demorando-se no } \\
\text { vale da indecisão ou no } \\
\text { pântano dos erros } \\
\text { numerosos. P. } 67\end{array}$ & $\begin{array}{l}\text { "The Umbral begins within } \\
\text { the earth's crust", he } \\
\text { obligingly continued. "It is a } \\
\text { zone for darkness for those } \\
\text { who, while on earth, were } \\
\text { not resolute in following the } \\
\text { path of their sacred duties in } \\
\text { order to fulfill them. Instead, } \\
\text { they lingered in the valley of } \\
\text { indecision or in the swamp of } \\
\text { numerous wrong-doings." P. } \\
94\end{array}$ & $\begin{array}{l}\text { Lysias continued: The Lower } \\
\text { Zone begins on the Earth } \\
\text { crust. It is the shadowy zone } \\
\text { for those who, in the world, } \\
\text { turned a deaf ear to the call } \\
\text { of their sacred duties, which } \\
\text { they failed to fulfill, } \\
\text { languishing instead in } \\
\text { indecision or dragging } \\
\text { themselves into the mire of } \\
\text { wrong-doings. P. } 56\end{array}$ \\
\hline
\end{tabular}

$\mathrm{Na}$ linguagem geral, segundo definição do dicionário online de língua portuguesa Aulete (UMBRAL c2017), a palavra "Umbral" significa: "1. Ombreira de porta; 2. Porta, entrada, limiar (umbrais da eternidade)" e corresponde à classificação morfológica de substantivo masculino. Na concepção espírita, de acordo com o site da FEB, ele é "situado entre a Terra e o Céu, [é] dolorosa 
região de sombras, erguida e cultivada pela mente humana, em geral rebelde e ociosa, desvairada e enfermiça" (VocÁBulos c2016). Outra definição foi trazida no livro objeto deste estudo (XAVIER 1992: 72): “A zona inferior a que nos referimos é qual a casa onde não há pão: todos gritam e ninguém tem razão".

$\mathrm{Na}$ língua inglesa, referente à linguagem comum, encontramos o termo threshold, cuja definição é semelhante à língua portuguesa. De acordo com o dicionário online Merriam-Webster (THRESHOLD c2018), consiste em: "1: the plank, stone, or piece of timber that lies under a door: sill; 2: gate, door" (1: tábua, pedra ou um pedaço de viga sob a porta: soleira; 2: portão, porta, tradução nossa). Já na concepção espírita, não encontramos, na língua inglesa, uma padronização na utilização do termo. Em sites especializados como o NorthWest Spiritism e o Unshakable-faith, encontramos o uso de Lower Zone. Entendemos que o Umbral pertence a uma das zonas inferiores existentes no plano espiritual; portanto, consideramos "Umbral" e "zona inferior" conceitos sinônimos e interpretamos que as duas traduções, Umbral e Lower Zone, estão corretas.

Vemos, então, que, mais uma vez, determinado termo assume significado específico se mencionado no contexto espírita.

Ao analisarmos o quadro 3, compreendemos que a Versão A optou por manter o termo original Umbral, porém com nota de rodapé explicativa, utilizando-se do procedimento tradutório denominado por Barbosa (2004) de transferência com explicação, que ocorre quando determinado vocábulo ou expressão que se refira a um conceito desconhecido para os falantes da língua traduzida é explicado através de notas de rodapé ou diluído no texto, facilitando assim, a compreensão dos leitores. Por sua vez, a Versão B optou por utilizar o termo Lower Zone, utilizando-se, assim, do procedimento técnico da equivalência, que, conforme Barbosa (2004: 67) "consiste em substituir um segmento de texto da LO por outro segmento da LT que não o traduz literalmente, mas que the é funcionalmente equivalente". Logo, apesar da inexistência de padronização dos termos específicos da doutrina espírita na língua inglesa, nesta análise conclui-se que ambos os termos Umbral e Lower Zone, por serem sinônimos, foram bem empregados nas duas 
versões e que seu uso depende da escolha do procedimento técnico que cada tradutor utiliza.

A análise dos termos específicos nos revela, por meio dos procedimentos utilizados, que a tendência da Versão A é de estrangeirizar a tradução, mantendo, assim, os traços culturais da língua estrangeira (VENUTI 2002). Enquanto a da Versão B é de domesticá-la, pois somente na presente categoria utilizou-se do procedimento de equivalência para todos os termos analisados, o que demonstra preocupação em eliminar os elementos que possam prejudicar seu entendimento, característica da domesticação, como vimos anteriormente.

A próxima categoria que será analisada é a das notas de rodapé.

\subsection{Notas de rodapé}

Como já vimos, as notas de rodapé podem ser feitas pelo autor e pelo tradutor. De qualquer maneira, elas buscam auxiliar o processo de compreensão dos leitores da língua original e da língua traduzida.

Primeiramente, apresentaremos as notas de rodapé feitas pelo autor do livro original. No total, são quatro (o livro é composto por 50 capítulos):

\section{Quadro 4 - Notas de rodapé do Autor Espiritual em português}

\begin{tabular}{|l|c|}
\hline Palavra selecionada - Texto original & Nota de rodapé - Texto original \\
\hline $\begin{array}{l}\text { Coração maravilhosamente azul } \\
\text { (Capítulo 3, p. 29) }\end{array}$ & $\begin{array}{c}\text { Imagem simbólica formada pelas } \\
\text { vibrações mentais dos habitantes da colônia. } \\
\text { (Nota do Autor espiritual.) }\end{array}$ \\
\hline $\begin{array}{l}\text { Aeróbus } \\
\text { (Capítulo 10, p. 59) }\end{array}$ & $\begin{array}{c}\text { Carro aéreo, que seria na Terra um } \\
\text { grande funicular. }\end{array}$ \\
\hline $\begin{array}{l}\text { Bônus-hora } \\
\text { (Capítulo 13, p. 76) }\end{array}$ & $\begin{array}{c}\text { Ponto relativo a cada hora de serviço. } \\
\text { (Nota do Autor espiritual.) }\end{array}$ \\
\hline $\begin{array}{l}\text { Samaritanos } \\
\text { (Capítulo 27, p. 147) }\end{array}$ & $\begin{array}{c}\text { Organização de Espíritos benfeitores } \\
\text { em Nosso Lar. (Nota do Autor espiritual.) }\end{array}$ \\
\hline
\end{tabular}


A literatura espírita, como já visto anteriormente, atua também como forma de doutrinação. 0 livro objeto deste estudo, portanto, também possui caráter de doutrinação, pois traz, detalhadamente, preciosas informações de como é a vida em Nosso Lar, de modo que, por todos os capítulos do livro, encontramos informações novas e termos específicos sendo introduzidos. Um exemplo é o termo "Umbral", que, como já mencionado, recebe um capítulo próprio para melhor elucidação do leitor.

Dessa maneira, a existência de poucas notas de rodapé no livro devese, provavelmente, ao fato de elas explicarem os poucos termos que ainda não tinham sido apresentados no corpo do texto para os leitores; e conceitos que também estavam sendo apresentados, naquele momento, para o autor espiritual, André Luiz. Vemos, ainda, que das quatro notas de rodapé, três possuem a informação de que foram feitas pelo autor espiritual, possivelmente para atestar que se trata de uma nota autoral e não editorial.

Observamos, no quadro abaixo, que as quatro notas do autor espiritual também estão nas versões $A$ e $B$, apresentando, ao leitor do texto traduzido, os mesmos dados apresentados aos leitores do texto original. Isso é importante porque as notas autorais, de acordo com Bastianetto (2005), fazem parte do texto, mesmo que o apenas contornem, e devem ser tratadas como tal na versão traduzida.

\section{Quadro 5 - Notas de rodapé nas traduções}

\begin{tabular}{|c|c|c|c|}
\hline $\begin{array}{c}\text { Palavra selecionada } \\
\text { NOSSO LAR - LIFE IN THE } \\
\text { SPIRIT WORLD } \\
\text { (Versão A) }\end{array}$ & $\begin{array}{c}\text { Nota de rodapé } \\
\text { NOSSO LAR - LIFE IN } \\
\text { THE SPIRIT WORLD } \\
\text { (Versão A) }\end{array}$ & $\begin{array}{c}\text { Palavra } \\
\text { selecionada } \\
\text { ASTRAL CITY } \\
\text { (Versão B) }\end{array}$ & $\begin{array}{l}\text { Nota de rodapé } \\
\text { ASTRAL CITY } \\
\text { (Versão B) }\end{array}$ \\
\hline $\begin{array}{l}\text { Wonderful blue heart } \\
\text { (Capítulo 3, p. 61) }\end{array}$ & $\begin{array}{l}\text { Symbolic image } \\
\text { formed by the mental } \\
\text { vibrations of the } \\
\text { inhabitants of the } \\
\text { colony - Spirit author }\end{array}$ & $\begin{array}{l}\text { Wonderful } \\
\text { heart, blue with } \\
\text { golden rays } \\
\text { (Capítulo } 3, \quad \text { p. } \\
\text { 25) }\end{array}$ & $\begin{array}{l}\text { Note by the spiritual } \\
\text { author: A symbolic } \\
\text { image created by the } \\
\text { mental vibrations of } \\
\text { the Colony. }\end{array}$ \\
\hline $\begin{array}{l}\text { Airbus (Capítulo 10, p. } \\
\text { 86) }\end{array}$ & $\begin{array}{l}\text { A sort of air-car that } \\
\text { would find its earthly } \\
\text { counterpart in a } \\
\text { cable-car. - Spirit } \\
\text { Auth. }\end{array}$ & $\begin{array}{l}\text { Airbus (Capítulo } \\
\text { 10, p. 48) }\end{array}$ & $\begin{array}{l}\text { An aerial vehicle } \\
\text { similar to our large } \\
\text { cable cars. }\end{array}$ \\
\hline Hour-bonuses (Capítulo & An amount related to & Many-bonuses & Note by André Luiz: \\
\hline
\end{tabular}




\begin{tabular}{|c|c|c|c|}
\hline 13, p. 100$)$ & $\begin{array}{l}\text { each hour of service - } \\
\text { Spiritual Auth. (See } \\
\text { chap. } 22 \text { for a full } \\
\text { explanation - Tr.) }\end{array}$ & $\begin{array}{l}\text { (Capítulo 13, p. } \\
62 \text { ) }\end{array}$ & $\begin{array}{l}\text { An hour-bonus is a } \\
\text { convention created to } \\
\text { account for each hour } \\
\text { of service performed } \\
\text { on behalf of the } \\
\text { community. }\end{array}$ \\
\hline $\begin{array}{l}\text { Samaritans } \\
\text { (Capítulo 27, p. 156) }\end{array}$ & $\begin{array}{l}\text { Organization of spirit } \\
\text { benefactors in Nosso } \\
\text { Lar - Spirit Auth. }\end{array}$ & $\begin{array}{l}\text { Samaritans } \\
\text { (Capítulo 27, p. } \\
\text { 119) }\end{array}$ & $\begin{array}{l}\text { Organization of spirit } \\
\text { benefactors in the } \\
\text { Astral City (a note by } \\
\text { the spirit author) }\end{array}$ \\
\hline
\end{tabular}

Apesar de as duas versões trazerem todas as notas de rodapé do texto original, a Versão B, na nota de rodapé do termo Airbus, omitiu que a mesma se tratava de uma nota de rodapé feita pelo autor espiritual, podendo, dessa forma, gerar uma pequena confusão para o leitor do texto traduzido. Por outro lado, a Versão A, na nota de rodapé do termo Hour-bonuses, acrescentou uma observação à nota de rodapé do autor espiritual, talvez porque entendeu que, mesmo assim, o leitor estrangeiro precisaria de uma explicação maior para o termo em questão.

Conforme analisamos acima, o autor espiritual trouxe ao texto original o total de quatro notas de rodapé e as mesmas também foram trazidas por ambas as versões. Porém elas não foram as únicas que os tradutores trouxeram no texto traduzido. A Versão A apresentou dez notas de rodapé, além das notas analisadas acima, e a Versão $B$ apresentou sete notas de rodapé, além das quatro do texto original. Entendemos que essas notas do tradutor representam, da mesma maneira, o caráter de doutrinação que a literatura espírita possui, principalmente em países de língua inglesa, onde ela é relativamente nova.

Traremos, a título de ilustração, três exemplos de cada tradução:

\section{Quadro 6 - Notas do tradutor}

\begin{tabular}{|c|l|l|l|}
\hline $\begin{array}{c}\text { Palavra selecionada } \\
\text { NOSSO LAR - LIFE IN THE } \\
\text { SPIRIT WORLD } \\
\text { (Versão A) }\end{array}$ & $\begin{array}{c}\text { Nota de rodapé } \\
\text { NOSSO LAR - LIFE IN } \\
\text { THE SPIRIT WORLD } \\
\text { (Versão A) }\end{array}$ & $\begin{array}{c}\text { Palavra } \\
\text { selecionada } \\
\text { ASTRAL CITY } \\
\text { (Versão B) }\end{array}$ & $\begin{array}{c}\text { Nota de rodapé } \\
\text { ASTRAL CITY } \\
\text { (Versão B) }\end{array}$ \\
\hline $\begin{array}{l}\text { Magnetic passes } \\
\text { (Capítulo 5, p. 69) }\end{array}$ & $\begin{array}{l}\text { Magnetic passes: } \\
\text { "..Passes are the } \\
\text { transmission of } \\
\text { spiritual and psychic }\end{array}$ & $\begin{array}{l}\text { Divine fluid } \\
\text { (Capítulo 3, p. p. }\end{array}$ & $\begin{array}{l}\text { In } \\
\text { terminology, fluid and } \\
\text { fluids designate a } \\
\text { substance r of }\end{array}$ \\
\hline
\end{tabular}




\begin{tabular}{|c|c|c|c|}
\hline & 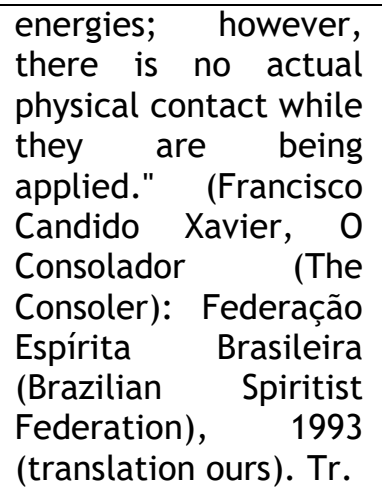 & & $\begin{array}{l}\text { magnetic nature that } \\
\text { can be manipulated } \\
\text { by both spiritual } \\
\text { beings and man on } \\
\text { Earth. }\end{array}$ \\
\hline $\begin{array}{l}\text { Subtle body } \\
\text { (Capítulo 5, p. 69) }\end{array}$ & $\begin{array}{l}\text { That is, the perispirit: } \\
\text { "The semi-material } \\
\text { envelope of the } \\
\text { spirit. Among } \\
\text { incarnates it serves as } \\
\text { the tie between the } \\
\text { spirit and matter. } \\
\text { Among discarnate } \\
\text { spirits it comprises } \\
\text { the spirits fluidic } \\
\text { body." (The Medium's } \\
\text { Book, chap. XXXII, } \\
\text { Spirit Glossary: } \\
\text { International Spiritist } \\
\text { Council, 2006) - Tr. }\end{array}$ & $\begin{array}{l}\text { Lower Zone } \\
\text { (Capítulo 4, p. } \\
\text { 27) }\end{array}$ & $\begin{array}{l}\text { Lower Zones are the } \\
\text { shadowy regions } \\
\text { where excessively } \\
\text { self-centered souls or } \\
\text { those with a guilty } \\
\text { ridden conscience } \\
\text { find themselves after } \\
\text { death (Translator } \\
\text { note) }\end{array}$ \\
\hline $\begin{array}{l}\text { Fashion designer's office } \\
\text { (Capítulo 20, p. 130) }\end{array}$ & $\begin{array}{l}\text { The reader would be } \\
\text { reminded that Laura's } \\
\text { remarks in this chapter } \\
\text { portray attitudes about } \\
\text { Brazilian home life in } \\
\text { the late } 19 \text { th and early } \\
\text { 20th centuries - Tr. }\end{array}$ & $\begin{array}{l}\text { Vampire } \\
\text { (Capítulo 31, p. } \\
\text { 139) }\end{array}$ & $\begin{array}{l}\text { By vampire the spirit } \\
\text { author refers to one } \\
\text { who extenguishes life } \\
\text { for personal } \\
\text { advantage (translator } \\
\text { note) }\end{array}$ \\
\hline
\end{tabular}

Por fim, analisaremos o procedimento técnico utilizado pela Versão A, presente em cinco das dez notas do tradutor e pela Versão $B$, presente em uma das sete notas do tradutor.

\section{Quadro 7 - Procedimento técnico nas notas do tradutor}

\begin{tabular}{|l|l|l|l|}
\hline $\begin{array}{c}\text { Palavra selecionada } \\
\text { NOSSO LAR - LIFE IN } \\
\text { THE SPIRIT WORLD } \\
\text { (Versão A) }\end{array}$ & $\begin{array}{c}\text { Nota de rodapé } \\
\text { NOSSO LAR - LIFE IN THE SPIRIT } \\
\text { WORLD } \\
\text { (Versão A) }\end{array}$ & $\begin{array}{c}\text { Palavra } \\
\text { selecionada } \\
\text { ASTRAL CITY } \\
\text { (Versão B) }\end{array}$ & $\begin{array}{c}\text { Nota de rodapé } \\
\text { ASTRAL CITY } \\
\text { (Versão B) }\end{array}$ \\
\hline $\begin{array}{l}\text { Nosso Lar } \\
\text { (Capítulo 2, p. 57) }\end{array}$ & $\begin{array}{l}\text { Portuguese for "Our home": a } \\
\text { full description of this service } \\
\text { colony is presented by the spirit } \\
\text { author in chapter 8 - Tr. }\end{array}$ & $\begin{array}{l}\text { Jacaranda } \\
\text { (Capítulo 49, } \\
\text { p. 220) }\end{array}$ & $\begin{array}{l}\text { High quality } \\
\text { Brazilian wood } \\
\text { (transl. Note) }\end{array}$ \\
\hline Umbral & $\begin{array}{l}\text { The Umbral is the region } \\
\text { situated between heaven and } \\
\text { earth. It is the doleful region of }\end{array}$ & & \\
\hline
\end{tabular}




\begin{tabular}{|l|l|l|l|}
\hline (Capítulo 8, p. 78) & $\begin{array}{l}\text { darkness built and cultivated by } \\
\text { the human mind, which is } \\
\text { generally rebellious, lazy, } \\
\text { confused and feeble... (Francisco } \\
\text { Candido Xavier, Action and } \\
\text { Reaction? International Spiritual } \\
\text { Council, 2010. See further } \\
\text { explanations in chap. 12 of the } \\
\text { present work). Tr. }\end{array}$ & & \\
\hline $\begin{array}{l}\text { Alvorada Nova } \\
\text { (Capítulo 11, p. 90) }\end{array}$ & Literally, New Dawn - Tr. & & \\
\hline $\begin{array}{l}\text { Harmonia } \\
\text { (Capítulo 17, p. 117) }\end{array}$ & Literally, Harmony - Tr. & & \\
\hline $\begin{array}{l}\text { Brazilian conto de réis } \\
\text { (Capítulo 27, p. 159) }\end{array}$ & $\begin{array}{l}\text { Conto de réis was the currency } \\
\text { in Brazil at the time - Tr. }\end{array}$ & & \\
\hline
\end{tabular}

Observamos que tanto a Versão A quanto a Versão B utilizaram, especificamente para as notas de rodapé acima, o procedimento técnico de transferência com explicação, que é empregada em notas de rodapé ou diluída no texto, para que o leitor aprenda seu significado através do contexto. Esse procedimento é explicado por Barbosa (2004: 74): “Muitas vezes, o TLO não permite esta compreensão, sendo necessário acrescentar ao TLT procedimentos adicionais à transferência para proporcionar ao leitor um entendimento do significado do mesmo".

Vemos, pela análise acima, com a manutenção dos termos em língua portuguesa e a utilização de notas de rodapé explicativas para os mesmos, que a Versão A tende a estrangeirizar o texto de chegada, mantendo os traços culturais da língua estrangeira (VENUTI 2002), enquanto a Tradução B evidencia o que observamos na maioria das análises, que essa versão tende ao processo de domesticação, utilizando outros procedimentos, como a equivalência e a adaptação, para a maioria dos termos para a língua traduzida.

\section{Considerações finais}

O objetivo deste trabalho foi analisar os procedimentos tradutórios utilizados em duas versões para a língua inglesa do livro Nosso Lar. Dividimos 
a análise em duas categorias: termos específicos e notas de rodapé, respectivamente.

Concluímos que, na primeira categoria, a Versão A utilizou-se mais do procedimento tradutório literal e a Versão $B$ utilizou-se mais da adaptação e da equivalência, entre outros procedimentos. A análise da última categoria foi a única em que ambos utilizaram apenas um único procedimento ao incluírem as notas do tradutor ao texto de chegada, o da transferência com explicação, utilizado cinco vezes pela Versão A e apenas uma pela Versão B. Observamos, dessa forma, que a Versão A demonstrou uma tendência em manter as características do texto original no texto traduzido, estrangeirizando-o, portanto. Por sua vez, a Versão B mostrou-se mais preocupada em adaptar o texto à cultura de chegada, domesticando-o.

Como já fora constatado no trabalho de Vieira e Jesus (2013), observamos também, neste estudo, que houve inconsistência na tradução dos termos específicos do espiritismo e que não houve padronização dos mesmos. Acreditamos que a Versão $A$ teve maior preocupação em cumprir o caráter de doutrinação do espiritismo trazendo mais notas de rodapé explicativas de conceitos da doutrina do que a Versão B, colaborando para a disseminação da doutrina espírita em países língua inglesa, onde ela é mais recente.

Com a realização deste estudo pretendemos contribuir para a área da tradução na literatura espírita que, embora crescente, ainda carece de estudos acadêmicos, bem como almejamos incentivar a realização de outros trabalhos. 


\section{Referências Bibliográficas}

Barbosa, H. Procedimentos técnicos da tradução: uma nova proposta. 2. ed. Campinas: Pontes, 2004.

BASTIANETTO, P. C. As funções do paratexto para a inteligibilidade da obra traduzida. Tradterm, São Paulo, v. 11, p. 53-69, 2005. Disponível em: <http://www.revistas.usp.br/tradterm/article/view/49676>. Acesso em: 02 out. 2016.

BrITTO, P. H. A tradução literária. Rio de Janeiro: Civilização Brasileira, 2012.

DISCARNATE. In: MERRIAM-Webster on-line dictionary. Springfield, MA: MerriamWebster, c2017. Disponível em: <https://www.merriamwebster.com/dictionary/discarnate>. Acesso em: 29 jul. 2016.

HISTÓRIA do espiritismo. FEB Editora, c2012. Disponível em: <http://www.febnet.org.br/blog/geral/o-espiritismo/historia-doespiritismo/> Acesso em: 03 mar. 2016.

KARDEC, A. O Livro dos Espíritos. 7. prova. Rio de Janeiro: Federação Espírita Brasileira, 2004. Disponível em: <http://www.febnet.org.br/wpcontent/uploads/2012/07/135.pdf>. Acesso em 02 nov. 2016.

Kardec, A. The Spirits' Book. Tradução Anna Blackwell. 6. ed. São Paulo: Federação Espírita Brasileira, 1996. Disponível em: < http://www.allankardec.com/Allan_Kardec/Le_livre_des_esprits/lesp _us.pdf>. Acesso em: 02 nov. 2016.

KüHL, E. Sinopse Nosso Lar. Instituto André Luiz, c2017. Disponível em: <http://www.institutoandreluiz.org/sinopse_nossolar.html>. Acesso em: 16 ago. 2016.

LeAL, J. C. Literatura Mediúnica e Literatura Espírita. Correio Espírita, mar. 2014. Disponível em: <http://www.correioespirita.org.br/categoriade-materias/artigos-diversos/1418-literatura-mediunica-e-literaturaespirita>. Acesso em 28 set. 2016.

LEWGOY, B. A transnacionalização do espiritismo kardecista brasileiro: uma discussão inicial. Religião \& Sociedade, Rio de Janeiro, v. 28, n. 1, p. 84-104, jul. $2008 . \quad$ Disponível em: <http://www.scielo.br/scielo.php?script=sci_arttext\&pid=S0100$85872008000100005 \&$ \&ng=en\&nrm=iso>. Acesso em: 07 out. 2016.

LUIz, A. Mortos Voluntários. Instituto André Luiz, c2017. Disponível em: <http://www.institutoandreluiz.org/evangelizando/passado_mortos_v oluntarios.html>. Acesso em: 07 out. 2016. 
MENSAGEIRO. 0 Mensageiro, c2016. Disponível em: <http://www.omensageiro.com.br/artigos/artigo-14.htm>. Acesso em 28 set. 2016.

OBSESSED. In: CAMBRIDGE Dictionary. Cambridge: Cambridge University Press, c2017. Disponível em: $<$ http://dictionary.cambridge.org/pt/dicionario/inglesportugues/obsessed?q=OBSESSED>. Acesso em: 26 set. 2016. Acesso em 02 nov. 2016.

OBSIDIADO. In: DICIONÁRIO online Caldas Aulete. Rio de Janeiro: Lexicon Editora Digital, c2017. Disponível em: <http://www.aulete.com.br/OBSIDIADO>. Acesso em: 26 set. 2016.

PIRES, H. Obsessão, o passe, a doutrinação. 10. ed. São Paulo: Editora Paidéia, 2009.

PIRES, H. Obsession, Passes, Counseling. Tradução Jussara Korngold e Marie Levinson. 1. ed. Nova York: Spiritist Alliance for Books, 2004.

QUEM somos. FEB Editora, c2012. Disponível em: <http://www.febeditora.com.br/quem-somos/> Acesso em: 03 mar. 2016.

SILVA, E. M. Fé e Leitura: a literatura espírita e o imaginário religioso. Campinas: [s.n.], 1997. Disponível em: <http://www.unicamp.br/ elmoura/biblio.htm>. Acesso em: 16 ago. 2016.

THRESHOLD. In: MERRIAM-Webster on-line dictionary. Springfield, MA: MerriamWebster, c2018. Disponível em: <https://www.merriamwebster.com/dictionary/threshold. Acesso em: 19 abr. 2018.

UMBRAL. In: DICIONÁRIO online Caldas Aulete. Rio de Janeiro: Lexicon Editora Digital, c2017. Disponível em: http://www.aulete.com.br/umbral>. Acesso em: 29 jul. 2016.

VeNUTI, L. Escândalos da tradução. Bauru: Edusc, 2002.

VIEIRA, M. A.; Jesus, S. M. J. Tradução de textos religiosos: um corpus paralelo do livro nosso lar, de Chico Xavier. Horizonte Científico, Uberlândia, v. 7, n. 1, set. 2013. Disponível em: <http://www.seer.ufu.br/index.php/horizontecientifico/article/view /22484>. Acesso em: 17 jul. 2016.

VoCÁBULOS e conceitos. Federação Espírita Brasileira, c2016. Disponível em: <http://www.febnet.org.br/site/az/AZ-Vocabulos-e-Conceitos.php>. Acesso em: 03 nov. 2016.

Xavier, F. C. Nosso Lar. Pelo Espírito André Luiz. 45. ed. Rio de Janeiro: Federação Espírita Brasileira, 1992. 
Xavier, F. C. Nosso Lar: Life in the spirit world. Pelo Espírito André Luiz. Tradução D. Kimble. 2. ed. Brasília: International Spirit Council, 2010.

XaVIer, F. C. The Astral City. Pelo Espírito André Luiz. 1. ed. eletrônica em inglês por Antônio Leite e GEAE (Grupo de Estudos Avançados de Espiritismo). Elon College, NC: Christian Spirit Center, 2000. Disponível em: <http://www.oconsolador.com.br/linkfixo/bibliotecavirtual/ingles/As tralCity.pdf>. Acesso em: 07 abr. 2016.

Recebido em: 05/09/2018

Aceito em: 20/09/2018 Publicado em outubro de 2018 